\title{
Editorial: Sense of agency: examining awareness of the acting self
}

\author{
Nicole David ${ }^{1}$, Sukhvinder Obhi ${ }^{2}$ and James W. Moore ${ }^{3 *}$ \\ ${ }^{1}$ Department of Neurophysiology and Pathophysiology, University Medical Center Hamburg-Eppendorf, Hamburg, Germany, \\ ${ }^{2}$ Department of Psychology, Neuroscience \& Behaviour, McMaster University, Hamilton, ON, Canada, ${ }^{3}$ Department of \\ Psychology, Goldsmiths, University of London, London, UK
}

Keywords: agency (psychology), volition, action, disorders, consciousness

For a long time interest in the sense of agency was confined to a small group of researchers such as philosophers of mind concerned with fundamental questions of consciousness and free will or neuropsychologists investigating mental illnesses that clearly involve abnormalities of agency (e.g., psychosis). This niche existence obscured the concept's relevance for many societal and cultural phenomena in which individuals experience subjective control over objectively uncontrollable events, or neglect control over events they have caused. It also resulted in a rather small number of scientific studies addressing the sense of agency. Today, scientific investigations of sense of agency constitute a rapidly expanding field. This is evident in the rising number of scientific articles related to the topic as listed on search engine databases such as PubMed.

Significant progress has been made with respect to some fundamental questions concerning the sense of agency, for example, in shedding light on the brain regions supporting sense of agency or in clarifying its conceptual boundaries. Yet, numerous questions remain unanswered. These include, but are not limited to, what neural network dynamics underlie the sense of agency, how does the sense of agency develop across the lifespan (e.g., in children compared to adults), and how can agency research be used in more applied domains, like engineering and computer science. The contributions in this research topic go some way to answering these questions. Here we provide a brief overview of these contributions, focusing on general themes that have emerged.

A number of contributions add to the theoretical literature on sense of agency. Some consider the applicability of Bayesian approaches to sense of agency (Friston et al., 2013; Moutoussis et al., 2014), an exciting development that promises to integrate agency research within a wider theoretical framework for understanding neurocognitive function. Other theoretical contributions have highlighted, and attempted to overcome, problems with existing models of agency processing (Carruthers, 2014; Chambon et al., 2014; Cioffi et al., 2014; Gentsch and Synofzik, 2014; Sowden and Shah, 2014; Swiney and Sousa, 2014). These cover a range of issues such as the affective dimension of agency processing (Gentsch and Synofzik, 2014) and the contribution of prospective (pre-motor) cues to sense of agency (Chambon et al., 2014). Collectively, these contributions demonstrate the relative maturity of theoretical work on sense of agency and how significant progress is being made in our understanding of it. Finally, other theoretical contributions have looked at more applied aspects of agency research, for example, the relevance of agency theory and methods for the field of human-computer-interaction, an exciting new arena in which to explore sense of agency (Limerick et al., 2014).

Amongst the original research articles, a large group of contributions used the so-called

Received: 03 March 2015 Accepted: 15 May 2015 Published: 03 June 2015

Citation: David N, Obhi S and Moore JW (2015) Editorial: Sense of agency: examining awareness of the acting self. Front. Hum. Neurosci. 9:310. doi: 10.3389/fnhum.2015.00310 Libet-clock to investigate sense of agency, with the majority focusing on the intentional binding effect (Barlas and Obhi, 2013; Cavazzana et al., 2014; Jo et al., 2014; Penton et al., 2014; Pfister et al., 2014; Hascalovitz and Obhi, 2015). Those contributions using intentional binding have done so in new and exciting ways, for example to assess agency processing in children (Cavazzana et al., 2014) and in social contexts (Pfister et al., 2014). However, intentional binding was not the only method used in our empirical contributions and important insights 
have been gleaned from a number of different methods such as the joint Simon effect and classical psychophysical measures together with Bayesian modeling (Kawabe, 2013; Stenzel et al., 2014). A particularly novel contribution used sensory attenuation to examine agency processing during lucid dreaming, pushing agency research into exciting new areas (Windt et al., 2014).

Additionally, a few contributions further examined the neural underpinnings of the sense of agency in methodologically novel and exciting ways. These have investigated the neural correlates of sense of agency as well as the neural networks supporting this experience (Dogge et al., 2014; Jo et al., 2014; RitterbandRosenbaum et al., 2014a,b). These contributions represent a significant advance in neuroimaging approaches to agency processing.

The final theme we have identified in the contributions centers around disorders of agency. These have extended the classical example of psychosis by discussing loss of agency in apraxia, anosognosia for hemiplegia and phantom-limb phenomena (Imaizumi et al., 2014; Pazzaglia and Galli, 2014; Preston and

\section{References}

Barlas, Z., and Obhi, S. (2013). Freedom, choice, and the sense of agency. Front. Hum. Neurosci. 7:514. doi: 10.3389/fnhum.2013.00514

Carruthers, G. (2014). What makes us conscious of our own agency? And why the conscious versus unconscious representation distinction matters. Front. Hum. Neurosci. 8:434. doi: 10.3389/fnhum.2014.00434

Cavazzana, A., Begliomini, C., and Bisiacchi, P. S. (2014). Intentional binding effect in children: insights from a new paradigm. Front. Hum. Neurosci. 8:651. doi: 10.3389/fnhum.2014.00651

Chambon, V., Sidarus, N., and Haggard, P. (2014). From action intentions to action effects: how does the sense of agency come about? Front. Hum. Neurosci. 8:320. doi: 10.3389/fnhum.2014.00320

Cioffi, M. C., Moore, J. W., and Banissy, M. J. (2014). What can mirror-touch synaesthesia tell us about the sense of agency? Front. Hum. Neurosci. 8:256. doi: 10.3389/fnhum.2014.00256

Dogge, M., Hofman, D., Boersma, M., Dijkerman, H. C., and Aarts, H. (2014). Cortical information flow during inferences of agency. Front. Hum. Neurosci. 8:609. doi: 10.3389/fnhum.2014.00609

Friston, K., Schwartenbeck, P., Fitzgerald, T., Moutoussis, M., Behrens, T., and Dolan, R. J. (2013). The anatomy of choice: active inference and agency. Front. Hum. Neurosci. 7:598. doi: 10.3389/fnhum.2013.00598

Gentsch, A., and Synofzik, M. (2014). Affective coding: the emotional dimension of agency. Front. Hum. Neurosci. 8:608. doi: 10.3389/fnhum.2014.00608

Hascalovitz, A., and Obhi, S. (2015). Personality and intentional binding: an exploratory study using scores on the narcissistic personality inventory. Front. Hum. Neurosci. 9:609. doi: 10.3389/fnhum.2015.00013

Imaizumi, S., Asai, T., Kanayama, N., Kawamura, M., and Koyama, S. (2014). Agency over a phantom limb and electromyographic activity on the stump depend on visuomotor synchrony: a case study. Front. Hum. Neurosci. 8:545. doi: 10.3389/fnhum.2014.00545

Jo, H.-G., Wittmann, M., Hinterberger, T., and Schmidt, S. (2014). The readiness potential reflects intentional binding. Front. Hum. Neurosci. 8:421. doi: 10.3389/fnhum.2014.00421

Kawabe, T. (2013). Side effect of acting on the world: acquisition of action-outcome statistic relation alters visual interpretation of action outcome. Front. Hum. Neurosci. 7:610. doi: 10.3389/fnhum.2013.00610

Limerick, H., Coyle, D., and Moore, J. W. (2014). The experience of agency in human-computer interactions: a review. Front. Hum. Neurosci. 8:643. doi: 10.3389/fnhum.2014.00643
Newport, 2014). There is also an important discussion of the utility of objective measures of sense of agency, such as intentional binding, in helping to improve our understanding of neurological disorders (Wolpe and Rowe, 2014). From these contributions it is becoming increasingly clear that aberrant experiences of agency are an important feature of numerous psychiatric and neurological disorders.

Taken together, this Research Topic demonstrates the impressive breadth of research currently being undertaken on sense of agency. The contributions themselves reveal the various applications, cross-disciplinary relevance and widespread significance of this topic. Sense of agency is now firmly on the agenda of psychologists, philosophers, computer scientists, neuroscientists, and neurologists/psychiatrists. However, despite the fact that significant progress has been made in our understanding of sense of agency and its real-world relevance, there is much work still to be done. Indeed this research topic serves as a record not only of where agency research is at present, but also as an indicator of where it can go in the future.

Moutoussis, M., Trujillo-Barreto, N. J. P., El-Deredy, W., Dolan, R., and Friston, K. (2014). A formal model of interpersonal inference. Front. Hum. Neurosci. 8:160. doi: 10.3389/fnhum.2014.00160

Pazzaglia, M., and Galli, G. (2014). Loss of agency in apraxia. Front. Hum. Neurosci. 8:751. doi: 10.3389/fnhum.2014.00751

Penton, T., Thierry, G. L., and Davis, N. J. (2014). Individual differences in attributional style but not in interoceptive sensitivity, predict subjective estimates of action intention. Front. Hum. Neurosci. 8:638. doi: 10.3389 /fnhum. 2014.00638

Pfister, R., Obhi, S. S., Rieger, M., and Wenke, D. (2014). Action and perception in social contexts: intentional binding for social action effects. Front. Hum. Neurosci. 8:667. doi: 10.3389/fnhum.2014. 00667

Preston, C., and Newport, R. (2014). Noisy visual feedback training impairs detection of self-generated movement error: implications for anosognosia for hemiplegia. Front. Hum. Neurosci. 8:456. doi: 10.3389/fnhum.2014. 00456

Ritterband-Rosenbaum, A., Karabanov, A. N., Christensen, M. S., and Nielsen, J. B. (2014a). $10 \mathrm{~Hz}$ rTMS over right parietal cortex alters sense of agency during self-controlled movements. Front. Hum. Neurosci. 8:471. doi: 10.3389/fnhum.2014.00471

Ritterband-Rosenbaum, A., Nielsen, J. B., and Christensen, M. S. (2014b). Sense of agency is related to gamma band coupling in an inferior parietalpreSMA circuitry. Front. Hum. Neurosci. 8:510. doi: 10.3389/fnhum.2014. 00510

Sowden, S., and Shah, P. (2014). Self-other control: a candidate mechanism for social cognitive function. Front. Hum. Neurosci. 8:789. doi: 10.3389/fnhum.2014.00789

Stenzel, A., Dolk, T., Colzato, L. S., Sellaro, R., Hommel, B., and Liepelt, R. (2014). The joint Simon effect depends on perceived agency, but not intentionality, of the alternative action. Front. Hum. Neurosci. 8:595. doi: 10.3389/fnhum.2014.00595

Swiney, L., and Sousa, P. (2014). A new comparator account of auditory verbal hallucinations: how motor prediction can plausibly contribute to the sense of agency for inner speech. Front. Hum. Neurosci. 8:675. doi: $10.3389 /$ fnhum. 2014.00675

Windt, J. M., Harkness, D. L., and Lenggenhager, B. (2014). Tickle me, I think I might be dreaming! Sensory attenuation, self-other distinction, and predictive processing in lucid dreams. Front. Hum. Neurosci. 8:717. doi: 10.3389/fnhum.2014.00717 
Wolpe, N., and Rowe, J. B. (2014). Beyond the 'urge to move': objective measures for the study of agency in the post-Libet era. Front. Hum. Neurosci. 8:450. doi: 10.3389/fnhum.2014.00450

Conflict of Interest Statement: The authors declare that the research was conducted in the absence of any commercial or financial relationships that could be construed as a potential conflict of interest.
Copyright $\odot 2015$ David, Obhi and Moore. This is an open-access article distributed under the terms of the Creative Commons Attribution License (CC BY). The use, distribution or reproduction in other forums is permitted, provided the original author(s) or licensor are credited and that the original publication in this journal is cited, in accordance with accepted academic practice. No use, distribution or reproduction is permitted which does not comply with these terms. 